\title{
Submitted:
0.10 .2020 Usefulness of high-frequency ultrasound in the monitoring Accepted: of laser treatment of acne scars
}

\author{
Sylwia Malinowska ${ }^{1}$, Dominika Jaguś2 ${ }^{2}$, Witold Woźniak ${ }^{3}$, \\ Robert Krzysztof Mlosek²
}

${ }^{1}$ Life-Beauty S.C., Grodzisk Mazowiecki, Poland

${ }^{2}$ Ultrasound Diagnostic Department Faculty of Medical Sciences Medical University

of Warsaw, Warsaw, Poland

${ }^{3}$ First Department of General and Vascular Surgery, Faculty of Medicine, Medical University of Warsaw, Poland

Correspondence: Robert Krzysztof Mlosek, Ultrasound Diagnostic Department Faculty of Medical Sciences, Medical University of Warsaw, Kondratowicza 8, 03-242 Warsaw, Poland; tel.+48601355 236,e-mail: mdchris@poczta.onet.pl

DOI: $10.15557 /$ JoU.2020.0049

\section{Keywords}

ultrasonography, skin,

lasers, scars, acne vulgaris

\begin{abstract}
Introduction: Acne scarring is considered one of the complications of acne vulgaris. Scarring is an important aesthetic problem for patients; therefore, effective methods for scar removal are sought. In recent years, laser methods for the treatment of acne scarring have become popular as a result of technological development. Monitoring and objective assessment of treatment outcomes are important elements of laser treatment. High-frequency ultrasonography is a diagnostic modality likely to become a common tool used for this purpose. Aim: The aim of this study was to assess the usefulness of high-frequency ultrasonography for the monitoring of laser treatment of acne scarring. Materials and methods: The study group included 7 patients (6 women and 1 man) aged 29-43 years with evident facial acne scarring. Each patient underwent laser treatment with Alma Harmony Er:Yag laser. Ultrasound examinations were performed with high-frequency DermaMed scanner. The following parameters were assessed on ultrasound images: the thickness of epidermis and dermis, the depth and width of scars. We additionally collected photographic documentation and assessed patient satisfaction with treatment outcomes. Results: The analysis of our findings showed statistically significant changes in the thickness of the epidermis and the depth of scars. No statistically significant results were obtained for the thickness of the dermis and the extent (width) of scars. The patients rated treatment outcomes as good. Conclusions: High-frequency ultrasonography is a useful method for the monitoring of laser treatment of acne scarring.
\end{abstract}

\section{Introduction}

Acne vulgaris is one of the most common skin conditions. Reports on acne date back to ancient times and may be found in the writings of Aristotle (5th century $\mathrm{BC})$ and Plinius (1st century BC) ${ }^{(1)}$. It is currently estimated that acne affects about $80 \%$ of population and is the reason for $30 \%$ of dermatological appointments ${ }^{(2)}$. Acne usually occurs in the second decade of life, with peak incidence between the ages of 14 and 17 years among girls and 16 and 19 years among boys. In recent years, there has been an increase in the incidence of acne in the age group $>20$ years $^{(3)}$. Acne vulgaris is a condition of complex, multifactorial etiology. It may be also associated with complications in the form of skin lesions, such as vascular and pigmented lesions, atrophic and hypertrophic scars, as well as keloids(2). Atrophic scars, which are usually found on the face, account for the majority of complications associated with collagen degradation. Hypertrophic scars, which most often appear on the trunk (shoulders in particular), are much less common ${ }^{(4)}$. 
Vascular and pigmented lesions have been observed to mostly resolve spontaneously over time ${ }^{(2)}$. Unfortunately, complications in the form of scars do not show this tendency and therefore are a serious aesthetic defect. They are not accepted by patients and have a negative impact on the mental condition and quality of life in many cases $^{(2,3)}$. Therefore, considering the prevalence of acne and its complications, as well as their unacceptability for patients, effective methods for the treatment of acne vulgaris and its complications have been sought for many centuries. Both, non-invasive (e.g. pharmacotherapy) and invasive (dermabrasion, cryotherapy, chemical peels) methods are used in the treatment of acne scarring ${ }^{(2)}$. Among invasive methods, laser therapies have become particularly popular in recent years, especially treatments performed with ablative fractional lasers, which are characterized by high efficacy, lower invasiveness and thus a lower risk of adverse effects ${ }^{(4,5)}$. However, regardless of the choice of the type of laser for the elimination of acne scars, doctors are faced with the lack of methods that would enable reliable and easy diagnosis of scars, as well as evaluation of therapeutic efficacy in everyday practice. So far, the majority of authors have used photographs and asked patients undergoing treatment about their satisfaction with therapeutic effects to assess acne scars and treatment outcomes ${ }^{(4,5)}$. High-frequency ultrasound (HFU) is a diagnostic modality that may fill this gap. HFU is objective, reliable and, most of all, safe for the patient, and it was shown to be useful in many areas of dermatology, cosmetology, and widely understood aesthetic medicine ${ }^{(6,7)}$. The aim of this study was to assess the usefulness of high-frequency ultrasound for the assessment of acne scarring and monitoring of the outcomes of erbium-YAG laser treatment.

\section{Materials and methods}

The study group included 7 patients with atrophic acne scarring of the face: 6 women and 1 man aged between 29 and 43 years (mean age 36.71 years). All patients in the study group had healed acne and no contraindications for laser treatment. For each patient, two scars were selected for ultrasonographic assessment; therefore a total of 14 scars were included in quantitative and qualitative analysis. Clinical assessment of scars was based on the classification system by Jacob et al. ${ }^{(8)}$ According to this classification, there are 3 types of atrophic acne scars: ice pick, rolling and boxcar. Ice pick scars are deep and narrow $(<2 \mathrm{~mm})$.

This type of scar is characterized by steep sides that narrow down to one point, which resembles a wound made with a skewer. Rolling scars are wide (4-5 $\mathrm{mm}$ ) and shallow. Boxcar scars are oval or round, with a diameter of 1.5 to $4 \mathrm{~mm}$. They have well-defined, sharp edges. These scars are usually shallow $(0.1 \mathrm{~mm}$ to $0.5 \mathrm{~mm})$. It should be noted, however, that deeper boxcar scars $(>0.5 \mathrm{~mm})$ may be also encountered $^{(8)}$.

All patients underwent laser treatment to reduce scars. Alma Harmony XL Pixel Er:Yag laser (Alma Lasers, Israel) with a wavelength of 2,940 $\mathrm{nm}$ was used. A fractional laser tip was used, emitting a beam divided into 49 microbeams on a $7 \times 7$ dot matrix, which covers an area of $11 \times 11 \mathrm{~mm}$ (Fig. 1). Long pulse (2 ms) treatment program with a frequency of $2 \mathrm{~Hz}$ and output pulse energy of 1600-1800 mJ/ pulse was used.

Emla anesthetic cream (Aspen Pharma) was applied on the entire facial surface about 40 minutes before the procedure. A total of 3 procedures were performed in each patient at 4-week intervals. During one procedure 3-4 laser passages were performed for a given scar. High-frequency ultrasound was performed twice - before the therapy and 4 weeks after the last treatment session, always in the same skin location. DermaMed (Dramiński S.A., Poland) scanner equipped with $48 \mathrm{MHz}$ mechanical transducer was used. The ultrasound images assessed the extent of the scar, its depth, and the thickness of the dermis and epidermis. We also recorded photographic documentation using the Fotomedicus system (Elfo, Poland). Additionally, the

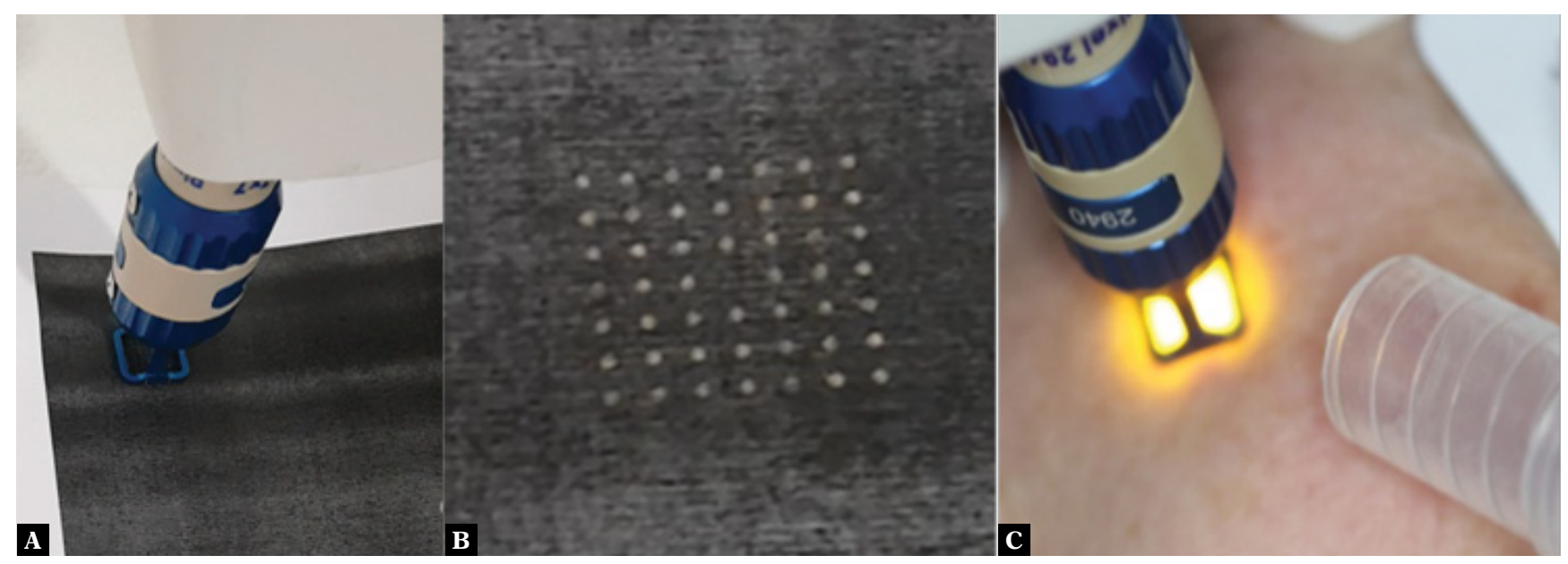

Fig. 1. Ablative fractional Er:YAG laser. A. Ablative fractional ER:YAG laser tip. B. $7 \times$ 7-point matrix-microdamage, obtained with one laser shot. $\mathbf{C}$. The use of a laser on the skin; the tip of the smoke evacuator can be seen (arrow) 


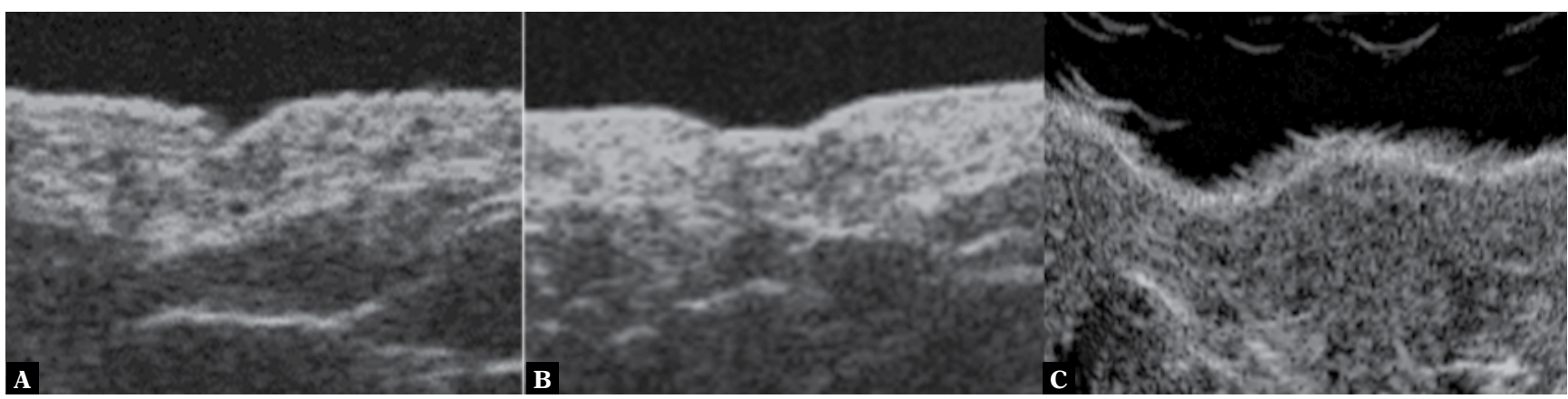

Fig. 2. Ultrasound image of acne scars. A. Ice pick scar. B. Boxcar scar. C. Rolling scars

patients were asked to rate their satisfaction with therapeutic outcomes on a 10-point score, where 1 stands for "not satisfied" and 10 stands for "very satisfied" with treatment outcomes.

No serious post-treatment complications occurred in the study group.

Statistica 13.3 was used for the analysis of the obtained results. The Shapiro-Wilk W test was used to verify the distribution of variables, and, once normal distribution was confirmed, the t-test was used for dependent samples. Statistically significant level was set at $\alpha=0.05$

\section{Results}

All scars were assessed based on the Jacob's scarring grading system and then verified against ultrasound images of the scars before the onset of laser therapy. Based on clinical assessment, there were 6 scars classified as ice pick scars, 6 scars classified as boxcar type and 2 rolling scars. Ultrasonography confirmed the clinical diagnosis in most cases (Fig. 2). In one case, a scar clinically diagnosed as ice pick type was interpreted in ultrasound as a boxcar scar.

Laser therapy led to a statistically significant difference in epidermal thickness (Tab. 1). The mean epidermal thickness was $0.13 \mathrm{~mm}$ before and $0.11 \mathrm{~mm}$ after treatment. This probably resulted from the sublimation of the epidermis leading to its thinning. No statistically significant changes were observed in the dermis thickness (Tab. 1).
However, a statistically significant result was obtained for scar thickness (Tab. 1, Fig. 3). The mean scar thickness was $0.36 \mathrm{~mm}$ before laser treatment and $0.29 \mathrm{~mm}$ ( $19.44 \%$ reduction) after treatment. Unfortunately, there was no statistically significant difference in the width of scars (Tab. 1).

Our findings indicate reduced scar width, which was 2.43 before treatment and 2.35 after treatment. However, the difference was not statistically significant.

After completing the therapy, treatment outcomes were rated by patients as good (satisfactory). A mean score of 5.43 (SD 1.72) was obtained on a 10-point score.

\section{Discussion}

We presented the possible uses of ultrasound for the assessment and monitoring of laser treatment of acne scars using ablative fractional Er:Yag laser. It can be concluded based on the obtained data that ultrasonography proved very useful in the evaluation of scars both before and after treatment. High-frequency ultrasound allowed for the assessment of the width and depth of acne scars in the first place.

Different scores used to assess the nature of scarring based on the observation of skin surface may be found in the literature ${ }^{(8,9)}$. Classification system by Jacob et al. ${ }^{(8)}$, which was used in our study, Goodman and Baron Qualitative scar grading system, Global Scale for Acne Scar Severity (SCAR-s) and Acne Scar Rating Scale

Tab. 1. Effects of laser acne scar removal based on parameters assessed in high-frequency ultrasound

\begin{tabular}{|c|c|c|c|c|c|c|c|}
\hline \multirow{2}{*}{ Variable } & \multirow{2}{*}{ Time point } & \multicolumn{6}{|c|}{ T-test for dependent samples, significant differences for $p<0.05$} \\
\hline & & Mean & SD & Min. & Max. & $\mathbf{t}$ & $p$ \\
\hline \multirow{2}{*}{ Epidermis thickness ( $\mathrm{mm}$ ) } & before & 0.13 & 0.02 & 0.09 & 0.16 & \multirow{2}{*}{5.264} & \multirow{2}{*}{$<0.001$} \\
\hline & after & 0.11 & 0.02 & 0.09 & 0.15 & & \\
\hline \multirow{2}{*}{ Dermis thickness (mm) } & before & 1.22 & 0,08 & 1.07 & 1.34 & \multirow{2}{*}{-1.018} & \multirow{2}{*}{0.327} \\
\hline & after & 1.23 & 0.09 & 1.11 & 1.45 & & \\
\hline \multirow{2}{*}{ Scar depth (mm) } & before & 0.36 & 0.12 & 0.16 & 0.56 & \multirow{2}{*}{7.727} & \multirow{2}{*}{$<0.001$} \\
\hline & after & 0.29 & 0.13 & 0.05 & 0.50 & & \\
\hline \multirow{2}{*}{ Scar width (mm) } & before & 2.43 & 1.09 & 0.93 & 4.28 & \multirow{2}{*}{1.985} & \multirow{2}{*}{0.069} \\
\hline & after & 2.35 & 1.05 & 0.95 & 3.97 & & \\
\hline
\end{tabular}




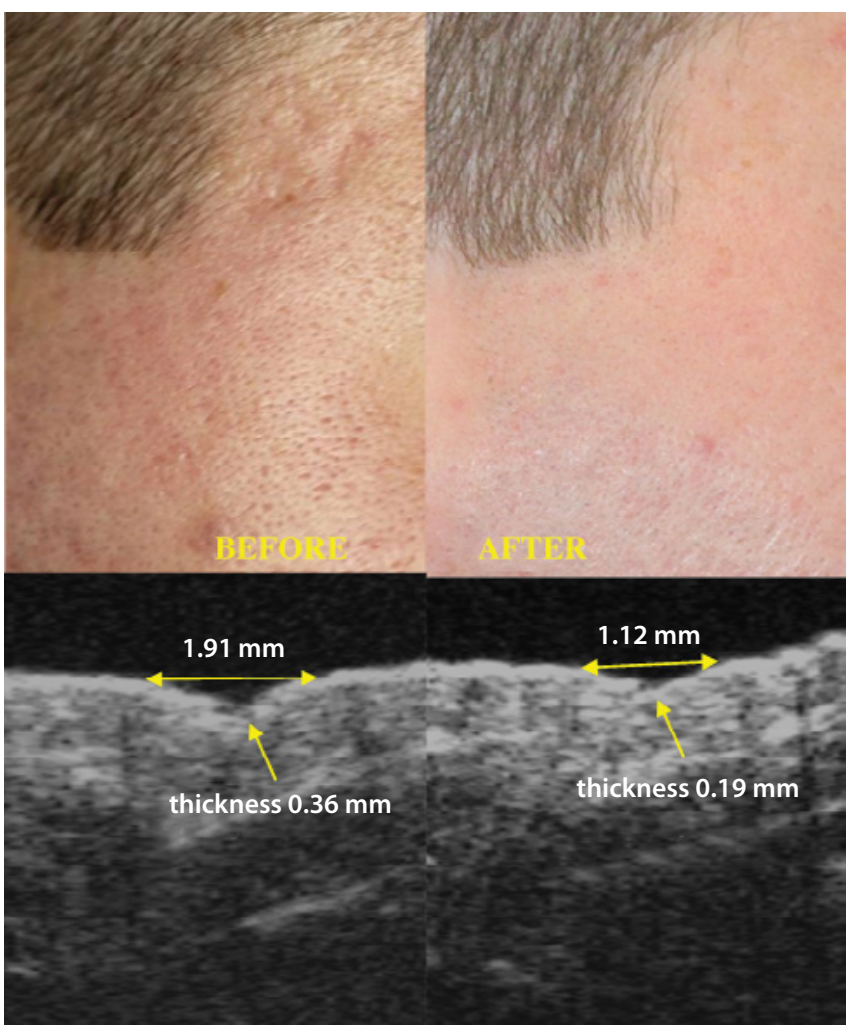

Fig. 3. The effects of therapy aimed at removing acne scars with ablative fractional Er:YAG laser

(ASRS) are the most commonly used classification systems $^{(9)}$. However, regardless of the type of score used for the assessment of acne scarring, evaluation of scar depth always poses challenge as it determines the choice of treatment method ${ }^{(8-10)}$. Previous attempts to measure scar depth were based on a three-dimensional analysis of photographic images ${ }^{(11)}$. A method proposed by Petukhova et al. involved taking three-dimensional photographs with specialized cameras(11). Although it allowed to obtain relatively reliable data, it did not become widely used. High-frequency ultrasonography, which was used in our study, and which provided data on the size and depth of scars, as supported by the obtained results, stands a chance of becoming an alternative to the previously used methods. The obtained data is reliable and accurate, and the examination itself may be repeated as it is non-invasive and completely safe for the patient. Our experiences show that the site and technique of examination are important to obtain reliable pre- and post-therapeutic results. The scan should always be performed in the same location as a few-millimeter shift may lead to conflicting results. We used a marker to mark the site of transducer application on the skin, as well as the site was appropriately described and photographed to enable accurate final examination of the same site. The pressure of the transducer on the scar being examined was another problem that occurred during scar depth assessment. High pressure could potentially flatten the scarred skin and thus generate false results. To minimize this problem, we applied a large amount of gel (which prevented the transducer from pressing against the skin surface). Additionally, the examination was always performed by the same operator. Our conclusions on the usefulness of ultrasonography in acne scar assessment are supported by Lacarrubba et al. The authors evaluated 81 acne scars based on Jacob's clinical grading system and performed ultrasonographic measurements using an ultrasound scanner with a $22 \mathrm{MHz}$ transducer. The ultrasound image corresponded with clinical diagnosis in many cases. However, $50 \%$ of scars classified as ice pick type in the clinical examination were classified as boxcar scars on ultrasound. This situation also occurred in one case in our study.

Ultrasonography also proved useful in the assessment of therapeutic outcomes. Ultrasound enabled us to assess changes occurring within the scars and the dermis. Here, in addition to the measurement of scar depth and width, measurements of the epidermis and dermis, which indicated proper skin remodeling in response to laser treatment, were also found useful ${ }^{(12)}$. These are parameters that can be used in future research to evaluate the usefulness of ablative fractional Er:YAG laser therapy. There are high hopes for the use of this type of laser in the treatment of acne scars. This results from the high effectiveness of fractional Er:YAG laser, as supported by previous studies. Hu et al. ${ }^{(13)}$ demonstrated that $72.7 \%$ of patients reported good and excellent improvement in the appearance of atrophic acne scars already after a single ablative fractional Er:YAG laser session. Patients' opinions were confirmed by doctors who reported good and very good treatment outcomes in $63.6 \%$, and fair treatment outcomes in $36.4 \%$ of cases. Furthermore, the efficacy of ablative fractional Er:YAG laser is comparable to that of fractional $\mathrm{CO}_{2}$ laser ${ }^{(5,14,15)}$. Faster healing process and almost complete absence of post-treatment complications are also an advantage of the Er:YAG laser over the $\mathrm{CO}_{2}$ laser. A study by Engin et al.(16), who used ultrasound also to assess buccal collagen density during ablative fractional Er:YAG laser treatment of acne scars, is also noteworthy. The authors used a scanner with a $22 \mathrm{MHz}$ mechanical transducer and showed an increase in buccal collagen density in the study group.

\section{Conclusions}

It may be concluded based on our findings as well as other authors' research that high-frequency ultrasonography is a useful tool for acne scar assessment and treatment efficacy monitoring. However, further research is needed due to the scarcity of scientific reports.

\section{Conflict of interest}

Authors do not report any financial or personal connections with other persons or organizations, which might negatively affect the contents of this publication and/or claim authorship rights to this publication. 


\section{References}

1. Czernielewski A: Zarys chorób skóry, błony śluzowej, jamy ustnej wenerycznych. PZWL. Warszawa 1982: 302-307.

2. Bartkowiak R, Halbina A, Kaszuba A, Kaszuba A: Zabiegowe i wspomagające metody leczenia trądziku pospolitego i zmian potrądzikowych. In: Adamski Z, Kaszuba A: Dermatologia dla kosmetologów. Elsevier Urban \& Partner. Wrocław 2010: 376-382.

3. Iwanek K: Trądzik pospolity. Lek Pol 2015; 25: 35-41.

4. Connolly D, Vu H, Mariwalla K, Saedi N: Acne scarring - pathogenesis, evaluation, and treatment options. J Clin Aesthet Dermatol 2017; 10: 12-23.

5. Yin R, Lin L, Xiao Y, Hao F, Hamblin MR: Combination ALA-PDT and ablative fractional Er:YAG laser $(2,940 \mathrm{~nm})$ on the treatment of severe acne. Lasers Surg Med 2014; 46: 165-172.

6. Polańska A, Dańczak-Pazdrowska A, Jałowska M, Żaba R, Adamski Z: Current applications of high-frequency ultrasonography in dermatology. Postepy Dermatol Alergol 2017; 34: 535-542.

7. Dopytalska K, Sobolewski P, Mikucka-Wituszyńska A, Gnatowski M, Szymańska E, Walecka I: Noninvasive skin imaging in esthetic medicine - why do we need useful tools for evaluation of the esthetic procedures. J Cosmet Dermatol 2020. Online ahead of print.

8. Jacob CI, Dover JS, Kaminer MS: Acne scarring: a classification system and review of treatment options. J Am Acad Dermatol 2001; 45: 109-117.

9. Clark AK, Saric S, Sivamani RK: Acne scars: how do we grade them? Am J Clin Dermatol 2018; 19: 139-144.
10. Thiboutot D, Gollnick H, Bettoli V, Dréno B, Kang S, Leyden JJ et al:: New insights into the management of acne: an update from the global alliance to improve outcomes in acne group. J Am Acad Dermatol 2009; 60 (5 Suppl): S1-50.

11. Petukhova TA, Foolad N, Prakash N, Shi VY, Sharon VR, O'Brecht L et al.: Objective volumetric grading of postacne scarring. J Am Acad Dermatol 2016; 75: 229-231.

12. Lacarrubba F, Verzì AE, Tedeschi A, Catalfo P, Nasca MR, Micali G: Clinical and ultrasonographic correlation of acne scars. Dermatol Surg 2013; 39: 1683-1688.

13. Hu S, Hsiao WC, Chen MC, Huang YL, Chang SL, Shih PY et al.: Ablative fractional erbium-doped yttrium aluminum garnet laser with coagulation mode for the treatment of atrophic acne scars in Asian skin. Dermatol Surg 2011; 37: 939-944.

14. Lapidoth M, Yagima Odo ME, Odo LM: Novel use of erbium:YAG $(2,940-\mathrm{nm})$ laser for fractional ablative photothermolysis in the treatment of photodamaged facial skin: a pilot study. Dermatol Surg 2008; 34: 1048-1053.

15. Manuskiatti W, Triwongwaranat D, Varothai S, Eimpunth S, Wanitphakdeedecha R: Efficacy and safety of a carbon-dioxide ablative fractional resurfacing device for treatment of atrophic acne scars in Asians. J Am Acad Dermatol 2010; 63: 274-283.

16. Engın B, Kutlubay Z, Karakuş Ö, Yardimci G, Doğan Z, Tüzün Y, Serdaroğlu S: Evaluation of effectiveness of erbium:yttrium-aluminumgarnet laser on atrophic facial acne scars with 22-MHz digital ultrasonography in a Turkish population. J Dermatol 2012; 39: 982-988. 